\title{
Light Trap Catches of Tenebrionids (Coleoptera tenebrionidae) with Reference to Species Diversity and Influence of Weather Factors
}

\author{
K. N. Muniswamy Gowda", O.R. Nataraju and R. Vinay Kumar \\ College of Agriculture, Hassan, Karnataka, India \\ *Corresponding author
}

\section{A B S T R A C T}

\section{Keywords \\ Tenebrionid beetles, \\ Temperature, \\ Saturation vapour pressure deficit, Rainfall, Light trap catch}

Article Info

Accepted:

30 May 2020

Available Online:

10 June 2020
Thirty two species of tenebrionid beetles were collected using light trap at College of Agriculture campus, Hassan. The activity of tenebrionids was more during new moon day when it is compared to full moon day as the ratio between them is 1.98:1.08. There was significant correlation $(\mathrm{r}=0.93)$ between $\log (\mathrm{catch}+1)$ and $\log$ radius for 1 to 6 hours, indicating that tenebrionid beetles are highly early fliers. The minimum temperature, maximum temperature, saturation vapour pressure deficit (SVPD) and rainfall had correlation of $+0.39,+0.096,-0.15$ and 0.60 respectively with light trap catches.

\section{Introduction}

Tenebrionidae is one of the largest families in the animal kingdom including more than 18,000 species in the world (Watt, 1974). Among these 300 species are recorded from India (Lefroy, 1909). Tenebrionidae is the versatile group, found in leaf mold, leaf litter, rotten wood, under bark stones and logs, feeding on decaying vegetation, dungs, seeds, cereals, fungi roots etc. during cooler hours of the day, or sometimes found walking on ground, in cracks, crevices, some sort of depressions on ground and some are nocturnal in habit.
Communities of these beetles integrate with factors such as availability of detritus, plant cover and various soil characteristics like moisture, hardness and grain storage composition. These factors differ for different species, for eggs and larvae too. We therefore expect tenebrionid beetles to be sensitive indicators of biodiversity change along with natural and anthropogenic gradients in dryer parts of southern Africa (Parenzee, 2001). Long term monitoring of their population can provide valuable insights into how environmental changes affect organism (Henschel et al., 2003). 
The research on tenebrionid beetles in India is scattered mainly describing the fauna of certain regions without much information on any other aspects of the tenebrionid beetles in India (Saha, 1990). Apparently nothing is known about their ecology, diversity and the important role played by these beetles in the ecosystem. Hence, a study was conducted for a peiod of two years from January 2017 to December 2018 at College of Agriculture campus, Hassan, Karnataka to findout tenebrionid beetle species getting attracted to light. The study was also aimed to find the influence of species diversity (in tenebrionid) and weather parameters on trap catch.

\section{Materials and Methods}

The Robinson light trap, run regularly for farecasting pests of College of Agriculture campus, Hassan. It was modified using 160 watt mercury lamp and used in the farm section of the campus for the present study to attract flying and nocturnal tenebrinoid beetles. The trap was regularly switched on at 18.30 hours everyday and was switched off in the next morning at 6.30 hours next morning. Daily the trap catches were removed soon after turning off the light and only tenebrinoid beetles were separated from trapped insects. Dichlorvos was used as killing agent that was replenished frequently. The specimens got identified using the input of specialist at British Museum (Natural History), London. Weather data were collected from the observatory at College of Agriculture, Hassan, which is near to light trap installation location. Correction of actual catch, calculation of ratio of new moon day to full moon day and trap radius were done using the procedure of Bowden (1973), Bowden and Church (1973), Bowden and Morris (1975). The corrected catches for each calendar day were grouped and weekly averages were calculated. The weekly mean $\log ($ catch +1$)$ were corrected with weather factors, namely weekly mean maximum and minimum temperature, weekly saturation vapour pressure deficit and total rainfall for the week of the respective weeks. A multiple linear regression analysis was applied to explain the variance due to individual weather parameters. The simple multiple linear regression model, $y=a+b^{1}+1+b^{2} X 2+b^{3} X$ $3+b^{4} X 4$ where $y 1, X 1, X 2, X 3$ and $X 4$ correspond to corrected mean $\log ($ catch +1$)$ mean maximum temperature $\left({ }^{0} \mathrm{c}\right)$, mean minimum temperature $\left({ }^{0} \mathrm{c}\right)$, mean saturation vapour pressure $(\%)$, deficit total rainfall (mm) respectively for that particular week were obtained.

\section{Results and Discussion}

During the study period, thirty two species of tenebrinoid beetles, of which fifteen new species (2 species under Allecula, 3 species under Gonocephalum, 4 species under Mesomorpha and one each under Caedius, Elixota, Opatroids and Sphingocorse genus including 2 genus et sp. Indet.) were caught in the light trap. The list of species collected with number of specimen is given in Table-1. Mesomorphus villiger was the predominant species trapped, followed by Opatroides frater. Both the species were found throughout the year. Other commonly noticed species were Adelina platisoides, Derosphaerus cancellatus, Cossyphus depressus and Elixota alternepicta.

The month-wise catch of tenebrinoid beetles during study period in light trap is given in Table-2. Maximum tenebrinoid beetles were caught in the month of September, followed by August month during both the years. The catch during rainy season was comparatively more suggesting maximum emergence of tenebrinoid beetles during this season.

Since, moon light affect the trap catch by reducing trap efficiency and by altering insect 
activity, influence of moon light on trap catches was studied. Totally 1916 tenebrinoid beetles were caught in 23 lunations i.e. period from one new moon to the other. The new moon to full moon ratio was 1.98:1.08 suggesting more activity of beetles around new moon. Number of beetles caught in new moon quarter, first quarter, full moon quarter and last quarter were 25, 21, 23 and 13 per cent, respectively.

Table.1 Tenebrionid beetles caught in light trap

\begin{tabular}{|c|c|c|}
\hline Sl. No. & Species & Number collected \\
\hline 1 & Allecula $s p_{1}$ & 3 \\
\hline 2 & Allecula $s p_{2}$ & 5 \\
\hline 3 & Adelina plastisoides (Pascoe) & 50 \\
\hline 4 & Caedius $s p$ & 6 \\
\hline 5 & Cossyphus depressus (Fabricius) & 30 \\
\hline 6 & Derosphaeus cancellatus Fairmaire & 33 \\
\hline 7 & Derosphaeus cribrum Fairmaire & 13 \\
\hline 8 & Elixota alternepicta (Fairmaire) & 25 \\
\hline 9 & Elixota navicularis (Fairmaire) & 12 \\
\hline 10 & Elixota sp. & 17 \\
\hline 11 & Eutochia pulla (Erichson) & 2 \\
\hline 12 & Gonocephalum minusculum & 11 \\
\hline 13 & Gonocephalum $s p_{1}$ & 17 \\
\hline 14 & Gonocephalum $s p_{2}$ & 16 \\
\hline 15 & Gonocephalum sp & 5 \\
\hline 16 & Himatismus fasciculatus (Fabricius) & 4 \\
\hline 17 & Leichenum canaliculaum (Fabricius) & 3 \\
\hline 18 & Lyprops curticollis Fairmaire & 2 \\
\hline 19 & Mesomorphus villiger (Blanchard) & 600 \\
\hline 20 & Mesomorphus $s p_{1}$ & 12 \\
\hline 21 & Mesomorphus sp 2 & 11 \\
\hline 22 & Mesomorphus sp 3 & 04 \\
\hline 23 & Mesomorphus $s p_{4}$ & 06 \\
\hline 24 & Microcrypticus ziczae (Motschulsky) & 31 \\
\hline 25 & Opatroides frater (Fairmaire) & 300 \\
\hline 26 & Opatroides sp. & 23 \\
\hline 27 & Scleron reitteri gebien & 02 \\
\hline 28 & Sphingocorse sp. & 03 \\
\hline 29 & Uloma polita (Wiedemann) & 02 \\
\hline 30 & Uloma rufilabris (Fairmaire) & 02 \\
\hline 31 & Genus et. $S p_{1}$ Indet. & 03 \\
\hline 32 & Genus et. $S p_{2}$ Indet. & 02 \\
\hline
\end{tabular}


Table.2 Monthly catch of tenebrionid beetles in light trap

\begin{tabular}{|l|c|c|}
\hline \multirow{2}{*}{ Month } & \multicolumn{2}{|c|}{ Beetles collected } \\
\cline { 2 - 3 } & $\mathbf{2 0 1 7}$ & $\mathbf{2 0 1 8}$ \\
\hline January & 8 & 7 \\
\hline February & 7 & 6 \\
\hline March & 80 & 77 \\
\hline April & 83 & 70 \\
\hline May & 90 & 83 \\
\hline June & 93 & 84 \\
\hline July & 105 & 100 \\
\hline August & 150 & 103 \\
\hline September & 303 & 200 \\
\hline October & 60 & 70 \\
\hline November & 45 & 40 \\
\hline December & 23 & 29 \\
\hline
\end{tabular}

Table.3 Correlation coefficient (r) between weather factors and light trap catches of Tenebrionidae

\begin{tabular}{|l|c|c|c|c|}
\hline \multirow{2}{*}{} & \multicolumn{4}{|c|}{ Weather factors } \\
\cline { 2 - 5 } & \multicolumn{2}{|c|}{ Temperature $\left(\mathbf{C}^{\mathbf{0}}\right)$} & S.V.P.W. & Rainfall (mm) \\
\cline { 2 - 5 } & Minimum & Maximum & \\
\cline { 2 - 5 } & $\mathbf{X}_{\mathbf{1}}$ & $\mathbf{X}_{\mathbf{2}}$ & $\mathbf{X}_{\mathbf{3}}$ & $\mathbf{X}_{\mathbf{4}}$ \\
\hline Actual catch & +0.08 & +0.28 & -0.03 & +0.30 \\
\hline Corrected catch & +0.096 & +0.39 & -0.15 & +0.45 \\
\hline
\end{tabular}

* Saturation Vapour Pressure Deficit

There was significant correlation $(\mathrm{r}=0.93)$ between $\log ($ catch +1$)$ and $\log$ trap radius for 1 to 6 hours of moon light indicating that tenebrinoid beetles are preponderatly early fliers. The line of best fit $\mathrm{y}=-0.45+0.025 \mathrm{X}$ was obtained which accounted for 75 per cent variance. Aldryhum et al., (1992) ported positive correlation between number of tenebrinoid beetles trapped and rainfall from Saudi Arabia. Similar correlation was used in the present study and the results are given in Table-3. The trap catches significantly correlated with minimum temperature $(+0.39)$ and total rainfall $(+0.45)$. The minimum temperature, maximum temperature, saturation vapour pressure deficit (SVPD) and rainfall showed the variance of $14.7,1.9,0.2$ and 33.3 per cent respectively. The linear regression model $\mathrm{y}=0.05-0.03 \mathrm{X} 1+0.08 \mathrm{X} 2+$ $0.09 \mathrm{X} 3+0.006 \mathrm{X} 4$ accounted for 21.3 per cent variance.

\section{References}

Aldryhum, Y.N., C.W. Mills and A.S. Aldawood, 1992, Ecological distribution and seasonality of darkling beetles (Coleoptera: Tenebrionidae) in central region of Saudi Arabia, J. Arid. Env. 23 (4): 415-422.

Bowden, J., 1973, The influence of moon light on catches of insects in light traps in 
Africa. Part-I: The moon and moon light, Bull. Ent. Res., 63: 113-128.

Bowden, J. and B.M. Church, 1973, The influence of moon light on catches of insects in light traps in Africa. Part-II: The effect of moon phase on light trap catches, Bull. Ent. Res., 63: 129-142.

Bowden, J. and M.G. Morris, 1975, The influence of moon light on catches of insects in light traps in Africa. Part-III: The effective radius of a mercury vapour light trap and the analysis of the catches using effective radius, Bull. Ent. Res., 65: 303-348.

Henschel, J.R., V. Mtuleni, J. Pallett and M.K. Seely, 2003, The surface-dwelling arthropod fauna of gobabeb with a description of the long-term pit fall trapping project, J. Nam. Sci. Soc., 51: 65-92.

Lefroy, H.M. 1909, Coleoptera. Indian Insect life, today and tomorrow's printers and publishers, New Delhi, pp. 335-339.

Parenzee, I., 2001, Use of Tenebrionid beetles as indicators of habitat quality, M.Sc. Thesis: University of Witwaters and Johannesburg.

Saha, G.N. 1990, Ethological and Ecological adaptations. In Taxonomy in Environment and Biology. Ed. Director, Zoological Survey of India, Calcutta, pp. 317-321.

Watt, J.C., 1974, A revised sub-family classification of Tenebrionidae (Coleoptera). N. Z. J. Zool,, 1: 381-452.

\section{How to cite this article:}

Muniswamy Gowda, K. N., O.R. Nataraju and Vinay Kumar, R. 2020. Light Trap Catches of Tenebrionids (Coleoptera tenebrionidae) with Reference to Species Diversity and Influence of Weather Factors. Int.J.Curr.Microbiol.App.Sci. 9(06): 4085-4089. doi: https://doi.org/10.20546/ijcmas.2020.906.478 